\title{
Unusual case of intraperitoneal round ligament fibroid, mimicking ovarian carcinoma
}

\author{
Ramneet Kaur*, Alka Patankar \\ Department of Obstetrics and Gynaecology, Indira Gandhi Government Medical College, Nagpur, India
}

Received: 28 April 2016

Accepted: 02 June 2016

\section{*Correspondence:}

Dr. Ramneet Kaur,

E-mail: ramneet.dr@gmail.com

Copyright: $\odot$ the author(s), publisher and licensee Medip Academy. This is an open-access article distributed under the terms of the Creative Commons Attribution Non-Commercial License, which permits unrestricted non-commercial use, distribution, and reproduction in any medium, provided the original work is properly cited.

\begin{abstract}
Round ligament leiomyoma are extremely rare benign tumors. It may present with wide range of clinical presentations depending on its site of origin, on the long course of round ligament. It has been reported round ligament leiomyoma commonly arises from extra peritoneal end of round ligament. There have been case reports where round ligament fibroid have presented like incarcerated inguinal hernia, vulvar swelling, inguinal lymph node. We present a case of intraperitoneal round ligament leiomyoma. A 40 year old female presented to gynecology Opd with a pain abdomen, abdominal distension and a mass of 26-28 weeks size gravid uterus, pelvic in origin. Her CA125 level was $185 \mathrm{U} / \mathrm{ml}$, CT abdomen suggested neoplastic ovarian tumor. With provisional diagnosis of ovarian carcinoma, patient was taken for exploratory laparotomy. Intraoperative findings suggested mass arising from intraperitoneal part of round ligament, with solid and cystic component and ascites. Bilateral ovaries and tubes were healthy and separately seen from mass. Histopathology report confirmed leiomyoma with hyaline and cystic degeneration. Large round ligament leiomyoma with degenerative changes can mimic ovarian carcinoma on imaging. A tissue biopsy or MRI before surgery can be of help.
\end{abstract}

Keywords: CA- 125, Leiomyoma, Ovarian carcinoma, Round liagament

\section{INTRODUCTION}

Fibroids or leiomyoma's are benign smooth muscle neoplasms that typically originate from uterine myometrium. Leiomyoma occur more frequently in reproductive age group. Extra-uterine leiomyoma originate from smooth muscles and usually arise in the genitourinary tract (in the vulva, broad ligament, round ligament, ovaries, urethra, and urinary bladder) but may arise in nearly any anatomic site. ${ }^{1}$ The round ligament extends from the uterus through the inguinal canal and terminates in the region of mons pubis and labia majora. It represents homolog of the gubernaculum testis. It has little to do with uterine support and is responsible for the descent of the ovary from the posterior abdominal wall to the uterus. ${ }^{2}$ It is mainly composed of smooth muscle fibres, connective tissue, vessels, and nerves with a mesothelial coating. ${ }^{3}$ There are only few case reports or case series available in literature, so the exact incidence is not known. ${ }^{1}$ Majority of the fibroids are asymptomatic. However the common symptoms of fibroids are menstrual disturbances, dysmenorrhea, and pressure symptoms caused by the mass. Round ligament fibroids have been found in abdomen, inguinal canal, and vulva thereby causing diagnostic confusion. ${ }^{4,5}$

\section{CASE REPORT}

Mrs. X, 40 year old female, married since 20 years, P4L4, presented to gynecology out-patient department with chief complaint of chronic pain in abdomen off and on, lump in abdomen since 3-4 months. Patient had no 
menstrual complaints. She had no history of bowel or bladder complaints. There was no history of weight loss, anorexia, or fever.

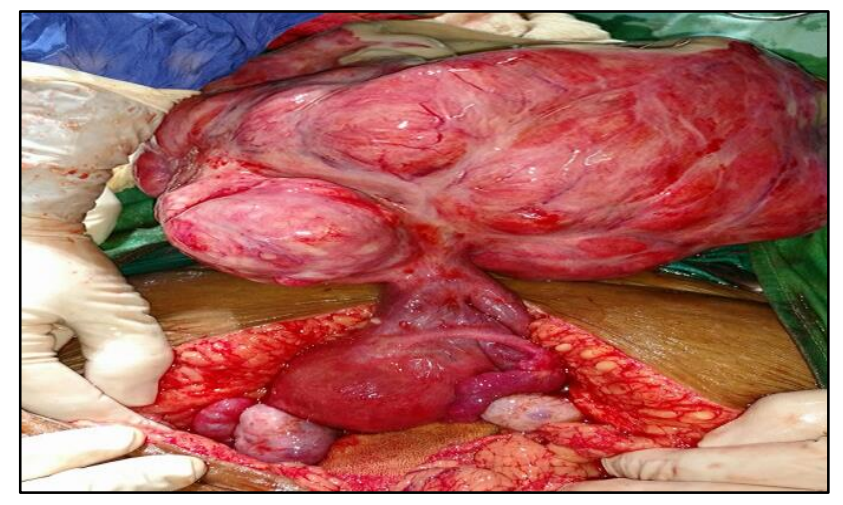

Figure 1: Origin of mass, thickened round ligament. Both the ovaries and tubes are healthy and separate from mass.

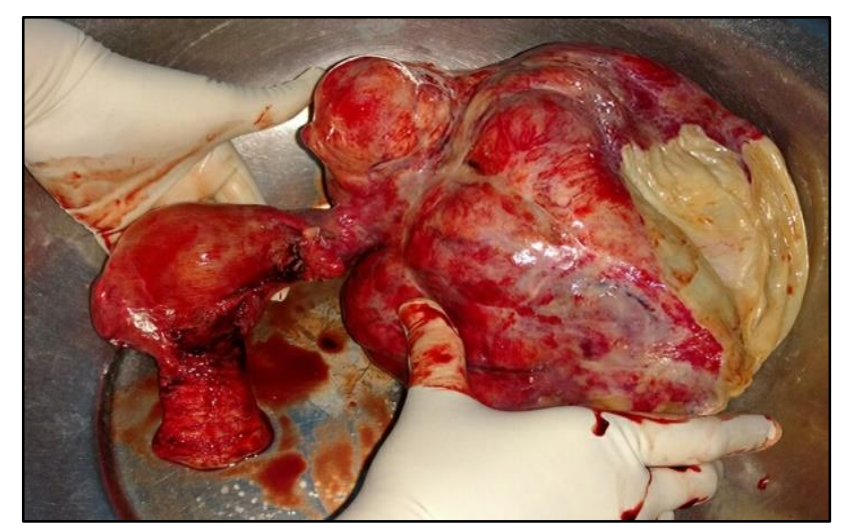

Figure 2: Resected specimen of uterus with leiomyoma showing degeneration.

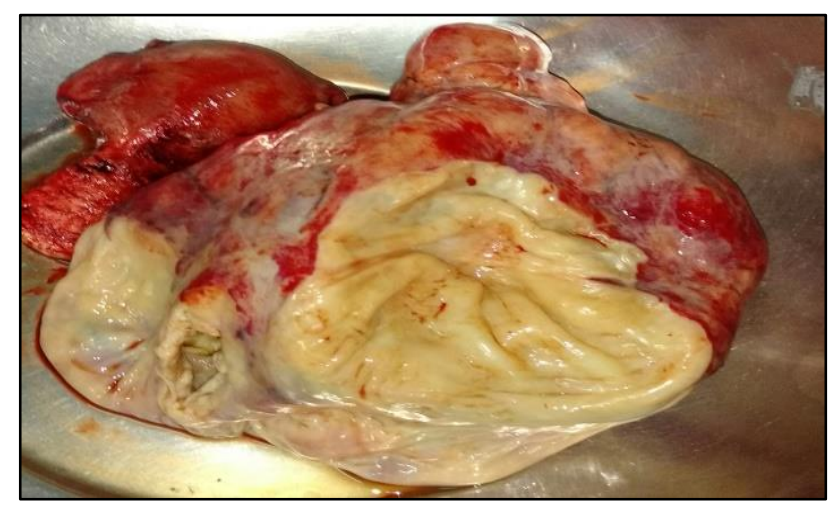

Figure 3: Myoma showing extensive degenerative changes.

Obstetric history of patient had 4 full term normal vaginal deliveries. Last child birth 17 years back. Tubal ligation was done 16 years back under spinal anaesthesia.
On examination general condition was fair the patient was afebrile, pulse 76/min, and blood pressure 130/80 $\mathrm{mmHg}$. Systemic examination was within normal limits.

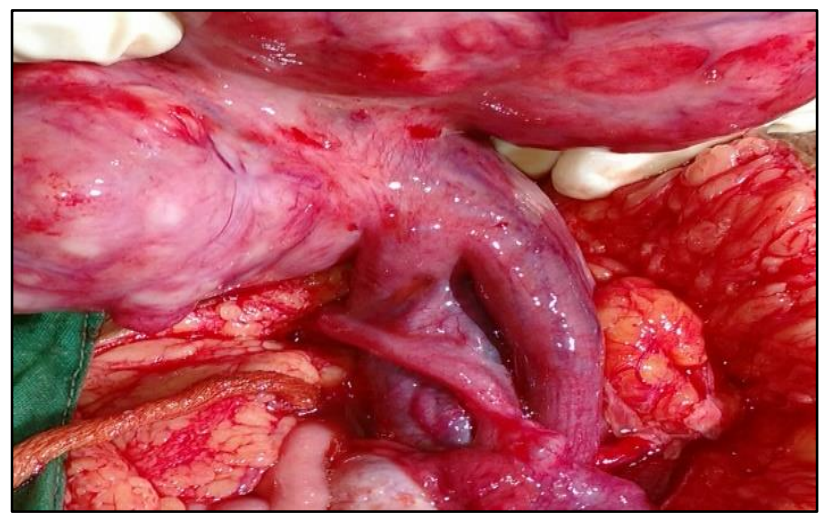

Figure 4: Site of origin of mass, thickened round ligament normal fallopian tube and ovary.

Per abdomen examination on inspection abdomen was distended. Palpation revealed a mass of 26-28 weeks size gravid uterus. Mass was variegated in consistency, nontender, had a restricted mobility with irregular margins. The lower pole of swelling could not be reached. Mass appeared to be arising from pelvis.

On speculum examination, cervix and vagina were healthy with no abnormal discharge.

On vaginal examination, uterus was retroverted deviated to the left, appeared normal size, and adhered to the mass. Mass could be lifted up during per vaginal examination. Non-tender mass was felt in all the fornices, more through the right anterior fornix and was mobile. Clinically, provisional diagnosis of ovarian mass was kept and patient was investigated further.

Routine blood analysis was within normal limits. Hemoglobin- 9.7 g/dl, TLC- 6500 /cumm, serum creat$0.4 \mathrm{mg} / \mathrm{dl}$. Urea- $7.9 \mathrm{mg} / \mathrm{dl}$, LFT- WNL. Hepatitis B surface antigen and HIV duo ultra were negative. Serum CA-125 (ovarian cancer antigen 125) value was 185.2 $\mathrm{U} / \mathrm{ml}$. C-Xray- suggestive of mild blunting of CP angle. Chest physician opinion was taken in view of $\mathrm{x}$-ray changes. Patient was advised USG thorax and PFT which was found with in normal limits.

\section{USG}

Uterus and left ovary normal size. Large encapsulated complex multiloculated multicystic lesion arising from pelvis, possibly right ovary, ascending upto the level of pancreas and laterally upto flank. Septations are thick measuring $1.4 \times 1.3 \mathrm{~cm}$ with nodularity within mural component noted with vascularity, S/O left ovarian malignant mass possibly seromucinous. 


\section{CT scan}

Abdomen and pelvis plain and contrast. Solid cystic mass in right adenexa of size $21.5 \times 20.7 \times 13.6 \mathrm{~cm}$ possibly arising from right ovary involving uterus with possible adhesions? Involving urinary bladder and adjacent ileal loop? Left ureter involvement and bilateral hydronenphrosis with multiple pelvis lymphadenopathies with minimal ascites with omental spread. Possibility of exophytic ileal mass could not be ruled out.

The CECT appearance was typical of cystic ovarian neoplasm. Final diagnosis based on the CECT scan of abdomen and pelvis and CA-125 levels was right ovarian neoplasm. With a provisional diagnosis of malignant ovarian tumour, the patient was taken up for an exploratory laparotomy.

Intra-operatively, an abdomino-pelvic mass of size approximately $27 \mathrm{~cm} \times 25 \mathrm{~cm} \times 14 \mathrm{~cm}$ was seen with variable consistency and increased vascularity, at the insertion of round ligament. Mass was a large sessile fibroid arising from right round ligament measuring 27 $\mathrm{cm} \times 25 \mathrm{~cm}$ x $14 \mathrm{~cm}$ with multiple cystic spaces. Largest being superior cystic mass measuring $14 \mathrm{~cm} \mathrm{x} 12 \mathrm{~cm}$, suggestive of cystic degeneration. Right sided round ligament was hypertrophied. Uterus, both sides fallopian tubes and ovaries were separately felt and seen. Uterus was enlarged around 8-10 weeks size. There was a small subserosal fibroid of $2 \mathrm{~cm} \times 2 \mathrm{~cm}$ size in the fundus of uterus. Both side ovaries and fallopian tubes were normal. Total abdominal hysterectomy was done and fibroid was removed along with the uterus and right side fallopian tube. Aspirated ascitic fluid was sent for cytology. Post-operative course was uneventful. Suture removal was done on day 10 . Patient was discharged on day 11 .

\section{Histopathology}

The surgically resected specimen included a large nodular cystic mass measuring $27 \mathrm{~cm} \times 24 \mathrm{~cm} \times 14 \mathrm{~cm}$, uterus and right sided fallopian tube. Nodular cystic mass weighed $6 \mathrm{~kg}$. On histopathological examination, the cut section of the mass showed solid fleshy areas and cystic areas filled with haemorrhage. The uterus revealed a small subserosal fibroid and multiple small intramural fibroids. The largest one measured $2 \mathrm{~cm} \times 2 \mathrm{~cm}$ and smallest $0.5 \mathrm{~cm}$ in diameter. Right fallopian tube was normal. Histopathology of the mass revealed interlacing bundles of smooth muscle cells, scattered thick-walled blood vessels, and evidence of cystic and hyaline degeneration. Histological features are suggestive of leiomyoma with areas of degeneration. Cervix showed a mild-to-moderate sub-epithelial lymphocytic infiltrate. There was no evidence of dysplasia or malignancy. Endometrium was in proliferative phase with simple cystic hyperplasia. Myometrial section revealed multiple intramural myomas of size $0.5-1 \mathrm{~cm}$.

\section{DISCUSSION}

Leiomyoma of the round ligament of uterus are benign, solid tumors which are rarely seen and they originate from smooth muscle fibers. ${ }^{6}$ And very few cases have been reported in literature. Approximately, one-half to two-thirds of leiomyomas occur in the extra-peritoneal portion of the round ligament and are more common on the right side for unknown reasons. ${ }^{7}$ Each leiomyoma is derived from a single progenitor myocyte. Leiomyoma are estrogen and progesterone sensitive. ${ }^{8}$ Hyperestogenic states are associated with growth and maintenance of leiomyoma. Recent research suggests that progesterone is the primary mitogen for tumor growth and that estrogen's role is to upregulate progesterone receptors. ${ }^{8,9}$ Both estrogen and progesterone receptors have been found in the round ligament. ${ }^{10}$

Ozer Birge et al. reported a case of 28 year old nulligravida with dyspareunia and a mass in anterior vaginal wall, which was diagnosed after histopathology as vulvar leiomyoma. Author concluded that leiomyoma can occur in any tissue or organ containing smooth muscle, spontaneously or parasitically after the spreading effect of an accident or surgical trauma. The author emphasized clinician should keep leiomyoma as a possibility for the diagnosis in a tissue with smooth muscle content. ${ }^{11}$

Renter'1a-Ruiz et al. reported a case of histopathologicaly revealed mesoectodermal leiomyoma located in the ciliary body in the right orbit, in a Mexican woman. When diagnostic workup suspected a solid mass resembling an adenoma. ${ }^{12}$

Harish et al. published case of left inguinal leiomyoma in a postmenopausal woman with a history of total hysterectomy done for uterine leiomyoma 18 years back. Patient was operated with provisional diagnosis of left inguinal degenerated cystic mass. The histopathological workup revealed a benign fibroid originating from round ligament. The authors emphasized the possibility of a newly developing leiomyoma in patients already operated for myoma uteri and the importance of a careful diagnostic workup. ${ }^{13}$

Nakamura et al described a patient who underwent bronchoscopical resection of a $14 \mathrm{~mm}$ tracheal tumor, for difficulty in swallowing. Pathological investigation of the mass revealed a leiomyoma. The authors warned against omitting leiomyoma from the differential diagnosis of tracheal tumors even if the prevalence was very low. ${ }^{14}$

Leiomyomas occasionally occur with unusual growth patterns or in unusual locations that make their identification more challenging both clinically and radiologically. ${ }^{1}$

For diagnosing leiomyoma most commonly used modality is sonography. On ultrasound leiomyoma shows 
a whorled pattern appearance with variable echogenicity, depending on the presence of degeneration and calcification. Four percent of fibroids undergo cystic degeneration with extensive edema forming cystic, fluidfilled spaces. In such cases, vessels bridging the mass and the myometrial tissue, termed bridging vessel sign are useful in diagnosing the case as leiomyoma. ${ }^{10}$ The differential diagnosis for round ligament fibroids includes ovarian mass (both benign and malignant), broad ligament fibroid and lymphadenopathy. Transvaginal ultrasound is helpful in such cases, as it can better visualize the mass, separate from uterus and ovaries.

Magnetic resonance imaging (MRI) is usually the best diagnostic modality, as it can exactly locate the origin of mass and differentiate round ligament fibroids from ovarian mass and broad ligament mass. Typical MRI appearance of fibroid can differentiate a round ligament fibroid from solid ovarian tumor. But confusion can persist in presence of degenerative changes. Degeneration and necrosis occurs in leiomyoma occurs because of limited blood supply within these tumors. ${ }^{8}$ Hyalinization is the most common type of degeneration occurring in $60 \%$ of cases. Cystic degeneration occurs in $4 \%$ of cases and is considered an extreme sequel of edema. ${ }^{15}$ This ability of MRI to differentiate leiomyoma from solid malignant pelvic tumors is important because broad ligament leiomyomas are associated with pseudo-Meigs syndrome and produce an elevated CA-125 level that may clinically mimic that in metastatic ovarian carcinoma, thereby causing diagnostic confusion. ${ }^{16}$ In present case patient presented with similar clinical picture (raised CA-125 level, Ascites and mimicking ovarian carcinoma). Typical leiomyomas demonstrate low to intermediate signal intensity on T1-weighted images and low signal intensity on T2-weighted images. ${ }^{1} \mathrm{CA}-125$ is a high molecular weight glycoprotein expressed on the cell surface of some derivatives of coelomic epithelium. In $90 \%$ of malignant non-mucinous ovarian tumors CA-125 levels are elevated. However CA-125 level is not specific for ovarian carcinoma, it can also be raised in leiomyoma, endometritis, pelvic inflammatory disease, pregnancy and even menstruation. ${ }^{17}$ Hence raised CA125 level can be misleading in case large leiomyoma, especially in presence of degenerative changes.

Ultrasound-guided percutaneous biopsy of the mass can help in determining the exact histology of mass.

\section{CONCLUSION}

A large round ligament fibroid is a rare entity and can be easily mistaken for ovarian neoplasm on clinical examination. In presence of extensive degenerative changes, these histologically benign tumors, may mimic malignant ovarian tumors on imaging and can present as a diagnostic challenge. So a differential diagnosis of round ligament leiomyoma should be considered in cases of ovarian masses with normal uterus, in absence of symptoms like anorexia and cachexia. CA-125 is not very sensitive marker of ovarian carcinoma and can be misleading. Like broad ligament fibroids, round ligament fibroids can also present with pseudo-meig's syndrome and elevated CA-125 pointing towards metastatic ovarian carcinoma, thereby causing diagnostic confusion. USG guided percutaneous biopsy and MRI should be done before planning a surgery in such cases.

Funding: No funding sources

Conflict of interest: None declared

Ethical approval: Not required

\section{REFERENCES}

1. Fasih N, Shanbhogue AKP, Macdonald DB, FraserHill MA, Papadatos D, Kielar AZ, et al. Leiomyomas beyond the uterus: unusual locations, rare manifestations. Radiographics. 2008;28(7):1931-48.

2. Rock JA, Jones HW, Te- Linde's. Operative Gynecology. $10^{\text {th }}$ edition. Philadelphia, PA,USA. Lippincott Williams and Wilkins; 2008:91.

3. Williams PL, Bannister LH, Berry MM, Collins P, Stain M, Dussek JE, et al. Editors. Grey's Anatomy. $38^{\text {th }}$ ed. New York: Churchill Livingston; 1995:1874.

4. Alexander L, Maria GHA, Christian K, Gerhard B, Johann L. Leiomyoma of the round ligament in a post-menopausal woman. Maturitas. 1999;31:133-5.

5. Ali SM, Malik KA, Al-Qadhi H, Shafiq $M$. Leiomyoma of the round ligament of the uterus. Sultan Qaboos Univ Med J. 2012;12(3):357-9.

6. Mettingly RF, Woodruff JO. Surgical conditions of the vulva. Rock JA, Jones HW eds in: Te Linde's Operative Gynecology. $10^{\text {th }}$ edition. Philadelphia, Pa, USA: Lippincott W and W; 2008:487-500.

7. David MW, Stanley RM. Leiomyoma of extraperitoneal round ligament: CT demonstration. Clin Imaging. 1999;23:375-6.

8. Hoffman BL, Schroge JO, Schaffer JI, Halvorson LM, Bradshaw KD, Cunningham FG. William's Gynecology. $2^{\text {nd }}$ edition. Texas: McGraw hill; 2012:247-252.

9. Ishikawa H, Ishi K, Serena VA, Kakazu R, Bulun SE, Kurita T. Progestrone is essential for maintenance and growth of uterine leiomyomata. Endocrinology. 2010;151(6):2433.

10. Smith P, Heimer G, Norgren A, Ulmsten U. The round ligament: a target organ for steroid hormones. Gynecol Endocrinol. 1993;7:97-100.

11. Birge O, Arslan D, Kinali E, Berk B. Round ligament of uterus leiomyoma: an unusual cause of dyspareunia. Case Reports in Obstetrics and Gynecology. 2015;2015:Article ID 197842.

12. Renter'1a-Ruiz NP, de Wit-Carter G, Villaseñor-Diez J, Flores-Estrada JJ, Rodríguez-Reyes AA. Mesectodermal leiomyoma. Unusual tumor of the ciliary body. Cirugia y Cirujanos. 2014;82(1):70-5.

13. Harish E, Sowmya N, Indudhara P. A rare case of round ligament leiomyoma: an inguinal mass. Journal of Clinical and Diagnostic Research. 2014;8(10):5-6. 
14. Nakamura Y, Hata Y, Koezuka S, Makino T, Otsuka $\mathrm{H}$, Sato F, et al. Tracheal leiomyoma resected with endobronchial electrocautery snare. Journal of Bronchology and Interventional Pulmonology. 2015;22(1):90-3.

15. Low SC, Chong CL. A case of cystic leiomyoma mimicking an ovarian malignancy. Ann Acad Med Singapore. 2004;33:371-4.
16. Brown RS, Marley JL, Cassoni AM. Pseudo-Meigs' syndrome due to broad ligament leiomyoma: a mimic of metastatic ovarian carcinoma. Clin Oncol (R Coll Radiol). 1998;10(3):198-201.

17. Hoffman BL, Schroge JO, Schaffer JI, Halvorson LM, Bradshaw KD, Cunningham FG. Epithelial ovarian cancer in William's Gynecology. $2^{\text {nd }}$ Edition. Texas: McGraw hill; 2012:860.

Cite this article as: Kaur R, Patankar A. Unusual case of intraperitoneal round ligament fibroid, mimicking ovarian carcinoma. Int J Reprod Contracept Obstet Gynecol 2016;5:2440-4. 